УДК 616-089.168.1(616.34-007.43)-371.7(616-089)

DOI 10.11603/2414-4533.2019.2.10413

(СС. С. ДАВЛАТОВ

Самаркандский государственный медицинский институт, Республика Узбекистан

\title{
Оценка качества жизни в отдаленном периоде у больных с послеоперационными вентральными грыжами
}

\begin{abstract}
Цель работы: анализ качества жизни пациентов по усовершенствованной шкале у больных с послеоперационными вентральными грыжами.

Материалы и методы. Основу для исследования составили 217 больных с послеоперационными вентральными грыжами, которые находились под наблюдением и поступившие в хирургические отделения 1 и 2 клиники Самаркандского государственного медицинского института в сроки с 2009 по 2017 год. Больные были разделены на две группы, которые в зависимости от вида герниопластики (аутогерниопластика или аллогернипластика) были распределены ещё на две подгруппы: 1 - группа сравнения - 135 больных (2009-2014 гг.), которым применены стандартные меры по предоперационной подготовке; 2 - основная группа - 82 больных (2015-2017 гг.), при лечении которых применён усовершенствованный алгоритм выбора оптимального способа хирургического лечения.

Результаты исследований и их обсуждение. После применение предложенных разработок и инновационных подходов качество жизни больных с послеоперационными вентральными грыжами, перенесших герниопластику, в основной группе улучшилось в отличие от пациентов группы сравнения.
\end{abstract}

Ключевые слова: послеоперационная вентральная грыжа; пневмобандаж; дубликатурный шов; качество жизни.

Постановка проблемы и анализ последних исследований и публикаций. В середине прошлого века возник интерес к проблеме качества жизни людей, страдающих различными заболеваниями. Затем они изучали не только распространение болезней, но и их влияние на профессиональную деятельность. Понятие качества жизни долгое время использовалось только в социальном аспекте и означало степень удовлетворенности работой, досугом, условиями жизни, уровнем удовлетворения потребностей в общении и т.д. [2, 3, 5].

Понятие “качество жизни” появилось в Index Medicus в 1977 году и широко используется в современном здравоохранении. Оно положено в основу новой парадигмы понимания болезни и больного и определения эффективности методов лечения. Качество жизни - интегральная характеристика физического, психологического, эмоционального и социального функционирования здорового или больного человека, основанная на его субъективном восприятии. Определение понятия качество жизни логично и структурно связано с дефиницией здоровья, данной Всемирной организацией здравоохранения (ВОЗ): “Здоровье - это полное физическое, социальное и психологическое благополучие человека, а не просто отсутствие заболевания" [2, 4].

В последние годы наблюдается значительный рост интереса к изучению качества жизни представителей различных отраслей медицины и значительное увеличение количества публикаций по этому вопросу. Методология исследования качества жизни предполагает применение стандарти- зированных опросников. В международной практике используют опросники, апробированные в клинических исследованиях. В зависимости от области применения опросники делят на общие (для детей и взрослых) и специальные - по областям медицины (кардиология, ревматология, онкология, неврология и т.д.), по нозологии (аритмии, ишемическая болезнь сердца, язвенная болезнь, ревматоидный артрит и т.д.), опросники, специфичные для определенных состояний $[3,4]$. Среди общих опросников оценки качества жизни наиболее распространены в клинической практике следующие:

- Профиль влияния заболевания - Sickness Impact Profile (SIP),

- Ноттингемский профиль здоровья Nottingham Health Profile (NHP),

- Шкала благополучия - Quality of Well-Being Scale,

- Шкала психологического благополучия Psychological Well-Being Schedule,

- Шкала беспокойства и депрессии - Hospital Anxiety and Depression Scale,

- Опросник здоровья МакМастера - McMaster Health Index Questionnaire,

- Общий опросник здоровья - MOS-SF-36.

Как видно из представленных опросников, большинство из них касается онкологических, сердечно-сосудистых заболеваний. У пациентов с хирургической патологией, в том числе людей страдающих большими и гигантскими вентральными грыжами, качество жизни является одним из 
главных показателей эффективности способа проведенного лечения. Несмотря на стремительноеразвитие малоинвазивных эндовидеохирургических технологий в абдоминальной хирургии, количество оперативных вмешательств с использованием традиционного лапаротомного доступа остается высоким, после которых в 4-18 \% случаев развиваются послеоперационные вентральные грыжи (ПОВГ), мы не встретили работ, посвященных изучению качества жизни пациентов у данной категории больных [1, 3, 4].

Материалы и методы. Исследование основано на клинико-лабораторном обследовании 217 больных с послеоперационными первичными и рецидивными вентральными грыжами, которые были оперированы в хирургических отделениях 1-й и 2-й клиники (Научный центр детской хирургии: главврач д. мед. наук Ж. А. Шамсиев) Самаркандского государственного медицинского института за период с 2009 по 2017 год. Все пациенты были оперированы в плановом порядке.

Больные были разделены на две группы:

1 - группа сравнения - 135 больных (20092014 гг.), которые в зависимости от вида герниопластики были распределены на две подгруппы: 1 подгруппу составили 38 (28,1 \%) больных с небольшими дефектами апоневроза, которым была произведена натяжная аутогерниопластика; 2 подгруппу составили 97 (71,9 \%) пациентов, которым применена аллогерниопластика с ушиванием дефекта апоневроза (натяжная) - 29 (21,5 \%) и без ушивания (ненатяжная) - 68 (50,4 \%) пациентов. В группе сравнения применены стандартные меры по предоперационной подготовке с учетом основных показателей функционального состояния ЖКТ, сердечно-сосудистой и дыхательной систем, включая подготовительное бандажиро- вание вправимых грыж $\left(\mathrm{W}_{2-4}\right)$ с использованием обычного бандажа в течение 5-14 суток.

2 - основная группа - 82 больных (20152017 гг.), распределенных наподгруппы по томуже принципу (аутопластика и аллопластика), но при лечении которых применен усовершенствованный алгоритм выбора оптимального способа хирургического лечения ПОВГ с учетом внедренных тактико-технических аспектов.

Распределение больных в группах сравнения по основным отличительным признакам представлено в таблицах 1 и 2.

Из 217 больных мужчин было 66 (30,4 \%), женщин - 151 (69,6 \%), а распределение по возрасту: до 45 лет - 40 (18,4 \%), 46-59 лет - 121 (55,8 \%), 60-74 лет -52 (24 \%), 75-90 лет - 4 (1,8 \%).

Всем больным проводили антропометрию с выявлением массы тела, которая важна для определения выбора хирургической тактики. Избыточную массы тела оценивали по классификации, предложенной экспертами ВОЗ. Из 217 больных нормальная масса тела была у 8 (3,7 \%) больных и 209 (96,3 \%) пациентов были с ожирением и избыточной массы тела.

В исследуемых группах 197 больных были с неосложненными формами грыжевого выпячивания и у 20 больных имело место такое осложнение, как невправимость. В наших наблюдениях такие осложнения, как ущемление грыжи и воспаление грыжевого мешка не наблюдалось.

Важнейшими факторами, определяющим хирургическую тактику, является локализация грыжи, размер дефекта и наличие рецидивов в анамнезе. Согласно классификации, J. P. Chervel и A. M. Rath y 83 (38,2 \%) больных были большие $\left(\mathrm{W}_{3}\right)$ и гигантские $\left(\mathrm{W}_{4}\right)$ грыжи [6]. Распределение больных по локализации грыжи, размеру дефекта и количеству рецидивов представлено в таблице 3.

Таблица 1. Распределение больных по группам сравнения

\begin{tabular}{||l|c|c|c|c||}
\hline \multirow{2}{*}{ Фактор отличия } & \multicolumn{2}{|c|}{$\begin{array}{c}\text { Группа сравнения } \\
\text { (n=135) }\end{array}$} & \multicolumn{2}{c|}{$\begin{array}{c}\text { Основная группа } \\
\text { (n=82) }\end{array}$} \\
\cline { 2 - 6 } & абс. & \% & абс. & \multicolumn{2}{c||}{} \\
\hline Сравнение результатов аутогерниопластики & 38 & 28,1 & 24 & 29,3 \\
\hline Сравнение результатов аллогерниопластики & 97 & 71,9 & 58 & 70,7 \\
\hline Предоперационная подготовка с использованием пневмобандажа & 0 & 0 & 52 & 63,4 \\
\hline Применение усовершенствованного иглодержателя & 0 & 0 & 28 & 34,1 \\
\hline Применение модифицированного дубликатурного шва & 0 & 0 & 24 & 29,3 \\
\hline Дополнение основного этапа операции висцеролизом & & & 21 & 25,6 \\
\hline Расширение показаний для ДлЭ при отвислом животе 3-4 ст. & 17 & 12,6 & 23 & 28,0 \\
\hline Применение разработанного тактического алгоритма & 0 & 0 & 82 & 100,0 \\
\hline Применение программы для оценки качества жизни после операции & 92 & 68,1 & 64 & 78,0 \\
\hline \hline
\end{tabular}


Таблица 2. Распределение больных по виду герниопластики

\begin{tabular}{|c|c|c|c|c|c|c|}
\hline \multirow{2}{*}{ Вид операции } & \multicolumn{2}{|c|}{1 подгруппа } & \multicolumn{2}{|c|}{2 подгруппа } & \multicolumn{2}{|c|}{ Всего } \\
\hline & абс. & $\%$ & абс. & $\%$ & абс. & $\%$ \\
\hline \multicolumn{7}{|l|}{ Группа сравнения } \\
\hline Натяжные способы пластики & 38 & 28,1 & 29 & 21,5 & 67 & 49,6 \\
\hline Пластика по Сапежко & 21 & 15,6 & 0 & 0,0 & 21 & 15,6 \\
\hline Пластика по Мейо & 17 & 12,6 & 0 & 0,0 & 17 & 12,6 \\
\hline Пластика дубликатурными швами в модификации клиники & 0 & 0,0 & 0 & 0,0 & 0 & 0,0 \\
\hline Имплантация эндопротеза “onlay” с ушиванием дефекта & 0 & 0,0 & 29 & 21,5 & 29 & 21,5 \\
\hline Ненатяжные способы & 0 & 0,0 & 68 & 50,4 & 68 & 50,4 \\
\hline Имплантация эндопротеза “onlay” без ушивания дефекта & 0 & 0,0 & 51 & 37,8 & 51 & 37,8 \\
\hline Имплантация эндопротеза “onlay” без ушивания дефекта + ДЛЭ & 0 & 0,0 & 17 & 12,6 & 17 & 12,6 \\
\hline $\begin{array}{l}\text { Имплантация эндопротеза “onlay” без ушивания дефекта с моби- } \\
\text { лизацией влагалищ прямых мышц живота по Ramirez + ДЛЭ }\end{array}$ & 0 & 0,0 & 0 & 0,0 & 0 & 0,0 \\
\hline Всего & 38 & 28,1 & 97 & 71,9 & 135 & 100 \\
\hline \multicolumn{7}{|c|}{ Основная группа } \\
\hline Натяжные способы пластики & 24 & 29,3 & 20 & 24,4 & 44 & 53,7 \\
\hline Пластика по Сапежко & 0 & 0,0 & 0 & 0,0 & 0 & 0,0 \\
\hline Пластика по Мейо & 0 & 0,0 & 0 & 0,0 & 0 & 0,0 \\
\hline Пластика дубликатурными швами в модификации клиники & 24 & 29,3 & 0 & 0,0 & 24 & 29,3 \\
\hline Имплантация эндопротеза “onlay” с ушиванием дефекта & 0 & 0,0 & 20 & 24,4 & 20 & 24,4 \\
\hline Ненатяжные способы & 0 & 0,0 & 38 & 46,3 & 38 & 46,3 \\
\hline Имплантация эндопротеза “onlay” без ушивания дефекта & 0 & 0,0 & 15 & 18,3 & 15 & 18,3 \\
\hline Имплантация эндопротеза “onlay” без ушивания дефекта + ДЛЭ & 0 & 0,0 & 12 & 14,6 & 12 & 14,6 \\
\hline $\begin{array}{l}\text { Имплантация эндопротеза “onlay” без ушивания дефекта с моби- } \\
\text { лизацией влагалищ прямых мышщ живота по Ramirez + ДЛЭ }\end{array}$ & 0 & 0,0 & 11 & 13,4 & 11 & 13,4 \\
\hline Всего & 24 & 29,3 & 58 & 70,7 & 82 & 100 \\
\hline
\end{tabular}

Таблица 3. Распределение больных по классификации J. P. Chervel и A. M. Rath

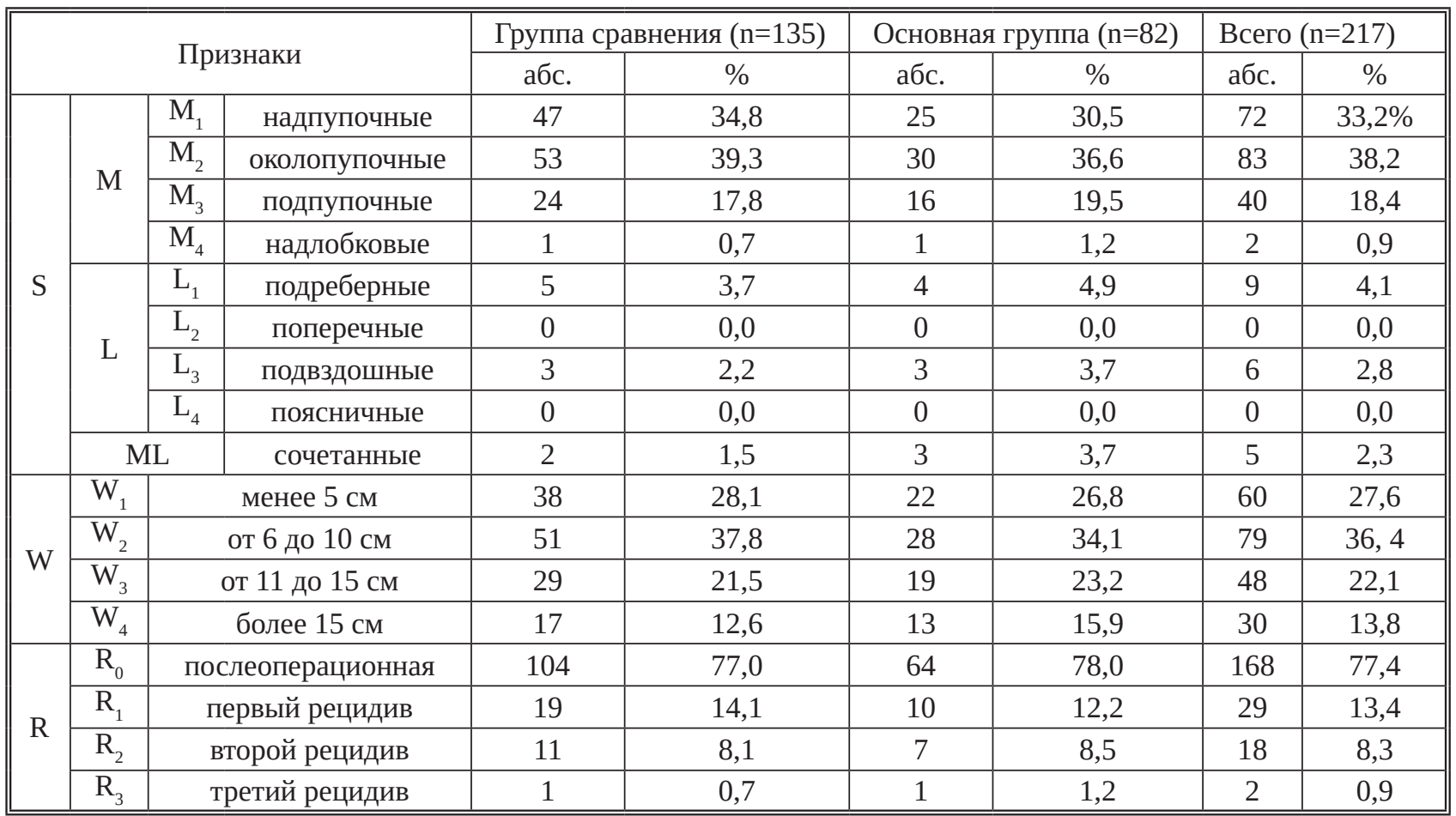


У подавляющего большинства больных (155 71,4 \%) были надпупочные $\left(\mathrm{M}_{1}\right)$ и околопупочные $\left(\mathrm{M}_{2}\right)$ грыжи. Наименьшее количество больных было с боковыми (L) 15 (6,9 \%) и сочетанными (M+L) 5 (2, 3\%) вентральными грыжами. Из 217 больных у 168 (77,4 \%) они были первичными ( $\left.\mathrm{R}_{0}\right)$ и у 49 (22,6 \%) больных - рецидивные $\left(\mathrm{R}_{\mathrm{n}}\right)$ грыжи.

Результаты исследований и их обсуждение. Одним из приоритетных направлений в современной медицине является включение в исследова- ние различных методик оценки качества жизни пациентов после проведенного консервативного или хирургического лечения. С 2012 года в нашей клинике определяется качество жизни пациентов, перенесших герниопластику, по разработанной программе, включающей в себя объективные и субъективные признаки, инструментальные данные, по которым можно оценить физическую, психическую и социальную повседневную деятельность пациентов, перенесших герниопластику (табл. 4, 5, рис. 1).

Таблица 4. Объективные критерии для определения качества жизни пациентов, перенесших герниопластику

\begin{tabular}{|c|c|c|}
\hline Критерии & Характеристика критерий & Баллы \\
\hline \multirow{3}{*}{$\begin{array}{l}\text { Состояние послеоперационной зоны по } \\
\text { инструментальным данным (УЗИ, КТ, МРТ) }\end{array}$} & Микроабсцессы & 3 \\
\hline & Инфильтрат & 7 \\
\hline & Патологий не выявлено & 10 \\
\hline \multirow[t]{3}{*}{ Характер стула } & Постоянные запоры & 3 \\
\hline & Периодические запоры & 7 \\
\hline & Нарушений нет & 10 \\
\hline \multirow[t]{3}{*}{ Объективный осмотр передней брюшной стенки } & Незаживление раны, свищ или рецидив & 3 \\
\hline & Грубый послеоперационный рубец & 7 \\
\hline & Нежный послеоперационный рубец & 10 \\
\hline \multirow[t]{3}{*}{ Пальпация послеоперационной зоны } & Сильные боли & 3 \\
\hline & Незначительные боли & 7 \\
\hline & Патологии не выявлено & 10 \\
\hline \multirow[t]{3}{*}{ Функциональное состояние дыхательной системы } & Хроническая дыхательная недостаточность & 3 \\
\hline & Периодические затруднение дыхания & 7 \\
\hline & Патологии не выявлено & 10 \\
\hline
\end{tabular}

Таблица 5. Субъективные критерии для определения качества жизни пациентов, перенесших герниопластику

\begin{tabular}{|c|c|c|}
\hline Критерии & Характеристика критерий & Баллы \\
\hline 1 & 2 & 3 \\
\hline \multirow{4}{*}{$\begin{array}{l}\text { Как Вы оцениваете общее состояние своего } \\
\text { здоровья? }\end{array}$} & Плохо & 0 \\
\hline & Удовлетворительно & 3 \\
\hline & Хорошо & 7 \\
\hline & Отлично & 10 \\
\hline \multirow{4}{*}{$\begin{array}{l}\text { Устраивает ли Вас косметический результат } \\
\text { операции? }\end{array}$} & Плохо & 0 \\
\hline & Удовлетворительно & 3 \\
\hline & Хорошо & 7 \\
\hline & Отлично & 10 \\
\hline \multirow[t]{4}{*}{ Как Вы в целом оцениваете результат операции? } & Плохо & 0 \\
\hline & Удовлетворительно & 3 \\
\hline & Хорошо & 7 \\
\hline & Отлично & 10 \\
\hline
\end{tabular}


Продолжение табл. 5.

\begin{tabular}{|c|c|c|}
\hline 1 & 2 & 3 \\
\hline \multirow[t]{4}{*}{ Как Вы оцениваете свою физическую активность } & Плохо & 0 \\
\hline & Удовлетворительно & 3 \\
\hline & Хорошо & 7 \\
\hline & Отлично & 10 \\
\hline \multirow[t]{4}{*}{ Чувство дискомфорта в послеоперационной зоне } & Постоянные сильные боли & 0 \\
\hline & Незначительные боли & 3 \\
\hline & Чувства дискомфорта & 7 \\
\hline & Жалоб нет & 10 \\
\hline
\end{tabular}

ПРОГРАММА ДЛЯ ОПРЕДЕЛЕНИЯ КАЧЕСТВА ЖИЗНИ ПАЦИЕНТОВ ПОС ЛЕ ПЕРЕНЕСЕННОЙ ГЕРНИОПЛАСТИКИ ПО ПОВОДУ ПОСЛЕОПЕРАЦИОННЫХ ВЕНТРАЛЬНЫХ ГРЬСК

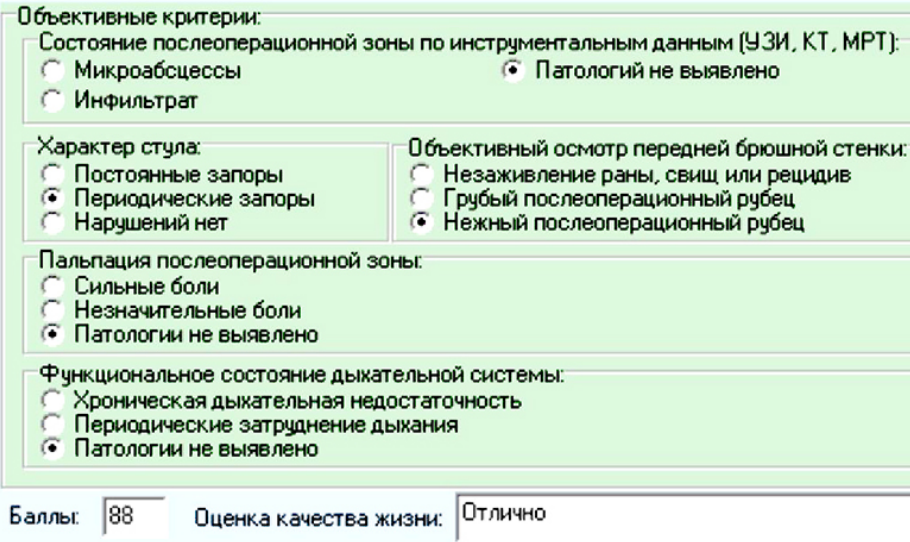

Рис. 1. Программа для определения качество жизни пациентов, перенесших герниопластику.

На данную программу получено свидетельство об официальной регистрации программы для ЭBM (№ DGU 05632, Агентство по интеллектуальной собственности Республики Узбекистан, 2018 год “Программа для определения качества жизни пациентов после перенесенной герниопластики по поводу послеоперационных вентральных грыж”).

По наличию набранных баллов из опросника по объективным и субъективным признакам в послеоперационном периоде оценивали качество жизни каждого больного. Больных набравших от 81 до 100 баллов оценивали как “отлично”, от 61 до 80 баллов - “хорошо”, от 41 до 60 баллов “удовлетворительно” и больные набравшие баллы ниже 40 оценивались как “неудовлетворительно”.

По разработанной программе определения качества жизни пациентов, перенесших герниопластику, оценены 156 (93,9 \%) из 166 больных, наблюдавших в отдаленном послеоперационном периоде. Из них 92 больных из группы сравнения и 64 больных из основной группы (табл. 6).

Таблица 6. Качество жизни пациентов в послеоперационном периоде

\begin{tabular}{|c|c|c|c|c|c|c|}
\hline \multirow{2}{*}{ Результат } & \multicolumn{2}{|c|}{$\begin{array}{c}\text { Группа сравнения } \\
(\mathrm{n}=92)\end{array}$} & \multicolumn{2}{|c|}{$\begin{array}{c}\text { Основная группа } \\
(\mathrm{n}=64)\end{array}$} & \multicolumn{2}{|c|}{ Всего (n=156) } \\
\hline & абс. & $\%$ & абс. & $\%$ & абс. & $\%$ \\
\hline Отлично & 30 & 32,6 & 35 & 54,7 & 65 & 41,7 \\
\hline Хорошо & 44 & 47,8 & 24 & 37,5 & 68 & 43,6 \\
\hline Удовлетворительно & 13 & 14,1 & 4 & 6,3 & 17 & 10,9 \\
\hline Неудовлетворительно & 5 & 5,4 & 1 & 1,6 & 6 & 3,8 \\
\hline Итого & 92 & 100,0 & 64 & 100,0 & 156 & 100,0 \\
\hline
\end{tabular}


Так, в группе сравнения отличные результаты были получены у 30 (32,6 \%) больных, хорошие у 44 (47,8 \%), удовлетворительные у 13 $(14,1 \%)$ пациентов и неудовлетворительные в 5 (5,4 \%) случаях. В свою очередь, в основной группе отличные результаты были получены у 35 из 64 (54,7 \%) больных, хорошие у 24 (37,5 \%), удовлетворительные у 4 (6,3%) пациентов и неудовлетворительные только в одном (1,6 \%) случае (рис. 2). По этому критерию была получена достоверная разница (значение критерия $\chi^{2}$ составило 8.961 с уровнем значимости $\mathrm{p}=0.030)$. Улучшение показателей качества жизни были получены по всем доменам шкалы с учетом психоэмоционального фона, а также физической активности пациентов после различных видов герниопластики. Все случаи рецидива заболевания независимо от общего статуса больных были зарегистрированы как неудовлетворительные результаты.

Таким образом, анализ качества жизни пациентов по усовершенствованной шкале показал, что применение алгоритма комплексного подхода к выбору оптимальной тактики лечения ПОВГ позволило увеличить долю “отличных и хороших” результатов с 80,4 \% (74 из 92 больных в группе сравнения) до 92,2 \% (59 из 64 больных в основной группе) исократить частоту неудовлетворительных исходов с 5,4 \% (5 из 92 больных в группе сравнения) до 1,6 \% (1 из 64 больных в основной группе) $(p=0,030)$.

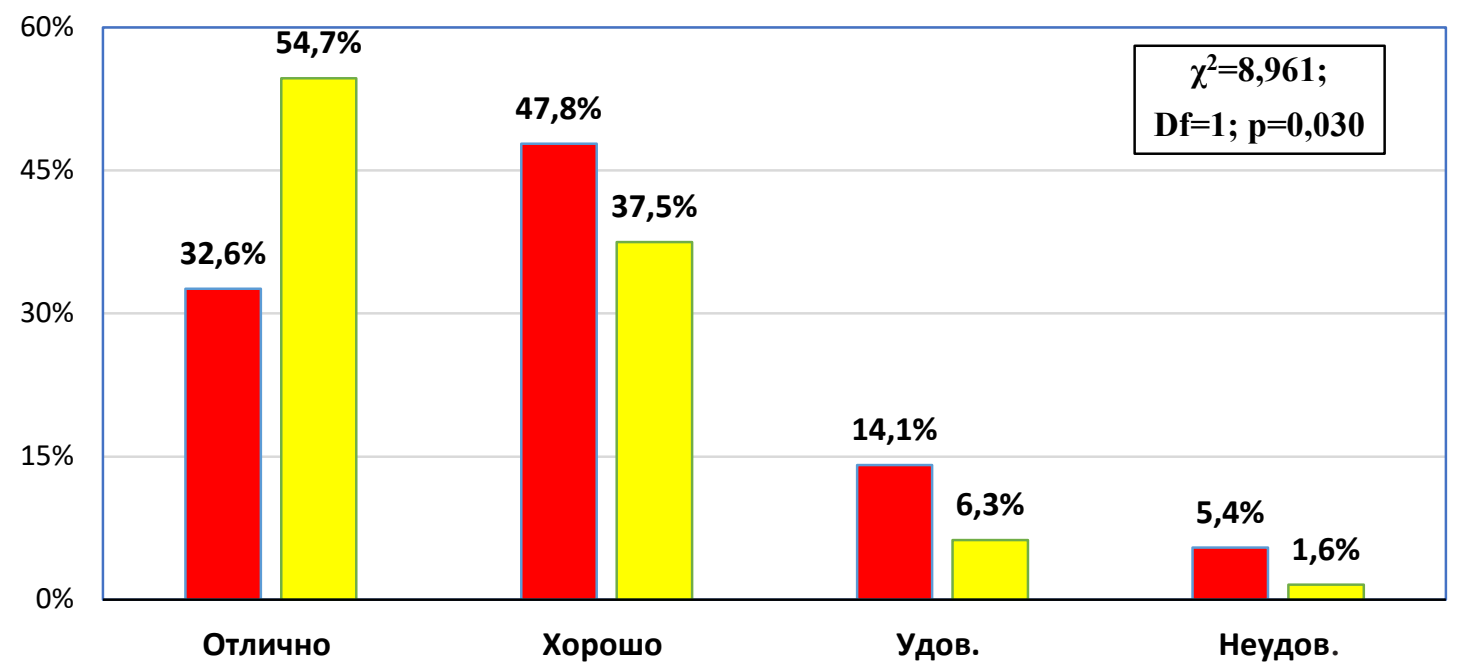

- Группа сравнения $\square$ Основная группа

Рис. 2. Качество жизни больных в зависимости от результатов герниопластики.

Выводы. Применение предложенного комплекса ведения больных с послеоперационными вентральными грыжами способствует снижению частоты послеоперационных осложнений с 19,7 до 3,6 \%, сокращению продолжительности хирургического вмешательства, уменьшению сроков стационарного лечения в два раза. Анализ качества жизни пациентов по усовершенствованной шкале показал, что применение алгоритма комплексного подхода к выбору оптимальной тактики лечения ПОВГ позволило увеличить долю “отличных и хороших” результатов с 80,4 \% до 92,2 \% и сократить частоту неудовлетворительных исходов с 5,4 до $1,6 \%(p=0,030)$.

\section{СПИСОК ЛИТЕРАТУРЫ}

1. Абдурахманов Ю. Х. Качество жизни больных послеоперационной вентральной грыжей в отдалённом периоде / Ю. Х. Абдурахманов, В. К. Попович, С. Р. Добровольский // Хирургия. Журнал им. Н. И. Пирогова. - 2010. - № 7. - С. 32-36. 2. Григорьева И. Н. Качество жизни у больных желчнокаменной болезнью в отдалённый период после холецистэктомии / И. Н. Григорьева, Т. И. Романова // Экспериментальная и клиническая гастроэнтерология. - 2010. - № 9. - С. 38-43.

3. Никонов С. Ф. Исследование качества жизни у пожилых больных после операции на сердце / С. Ф. Никонов, И. Е. Олофинская, Л. С. Багиян // Качественная клиническая практика. - 2008. - № 1. - С. 56-59.
4. Новик А. А. Исследование качества жизни в клинической медицине / А. А. Новик, Т. И. Ионова // Вестник национального медико-хирургического центра им. Н. И. Пирогова. - 2006. - T. 1. - № 1. - С. 91-99.

5. Шапошников Ю. Ю. Исследование качества жизни больных после хирургического лечения / Ю. Ю. Шапошников, Н. Ю. Шапошников //Астраханский медицинский журнал. - 2010. - Т. 5. - № 1. - С. 115-122.

6. Современная концепция лечения больных с гигантскими послеоперационными вентральными грыжами / 3. Б. Курбаниязов, С. С. Давлатов, 3. А. Абдураимов, Ш. А. Усаров // Проблемы биологии и медицины. - 2016 - №. 1. - С. 112- 121. 


\section{REFERENCES}

1. Abdurakhmanov, Yu.Kh., Popovich, V.K., \& Dobrovolskiy, S.R. (2010). Kachestvo zhyzni bolnykh posleoperatsionnoy ventralnoy gryzhey $\mathrm{v}$ otdalenom periode [Long-term quality of life of patients with postoperative ventral hernia]. Khirurgiya. Zhurnal imeni N.I. Pirogova - Surgery. N.I. Pirogov Journal, (7), 32-36 [in Russian].

2. Grigoryeva, I.N., \& Romanova, T.I. (2010). Kachestvo zhizni u bolnykh zhelchnokamenoy boleznyu $\mathrm{v}$ otdalenyy period posle kholetsistektomii [Long-term quality of life of patients after cholecystectomy]. Eksperementalnaya i klinicheskaya gastroenterologiya-Experimental and Clinical Gastroenterology, (9), 38-43 [in Russian].

3. Nikonov, S.F., Olofinskaya, I.E., \& Bagiyan, L.S. (2008). Issledovaniye kachestva zhizni u pozhylykh bolnykh posle operatsii na serdtse [Study of quality of life in patients after heart surgery]. Kachestvennaya klinicheskaya praktika - Qualitative
Clinical Practice, (1), 56-59 [in Russian].

4. Novik, A.A., \& Ionnova, T.I. (2006). Issledovaniye kachestva zhizni v klinicheskoy meditsine [Study of quality of life in clinical medicine]. Vestnik natsionalnogo mediko-khirurgicheskogo tsentra im. N.I. Pirogova - Bulletin of N.I. Pirogov National Medical \& Surgical Center, 1 (1), 91-99 [in Russian].

5. Shaposhnikov, Yu.Yu., \& Shaposhnikov, N.Yu. (2010). Issledovaniye kachestva zhizni bolnykh posle khirurgicheskogo lecheniya [Study of quality of life of patients after surgical treatment]. Astrakhanskiy meditsinskiy zhurnal - Astrakhan Medical Journal, 5 (1), 115-122 [in Russian].

6. Kurbaniyazov, Z.B., Davlatov, S.S., Abduraymov, Z.A., \& Usarov, Sh.A. (2016). [Sovremennaya kontseptsiya lecheniya bolnykh s gigantskimi posle operatsionymi gryzhami]. Problemy biologii i meditsiny - Problems of Biology and Medicine, (1), 112-121 [In Russian].

Получено 18.03.2019

Электронный адресс для переписки: davlatov@umail.uz

\section{S. S. DAVLATOV}

Samarkand State Medical Institute, Republic of Uzbekistan, Samarkand

\section{ASSESSMENT OF QUALITY OF LIFE IN THE LONG TERM IN PATIENTS WITH POSTOPERATIVE VENTRAL HERNIAS}

The aim of the work: to analyze the quality of life of patients on an improved scale in patients with postoperative ventral hernias. Materials and Methods. Study involved 217 patients with postoperative ventral hernias of comparable age who were under observation and admitted to the department of the surgical departments of the 1st and 2nd clinics of Samarkand State Medical Institute in 2009-2017. All patients were randomized on two groups, which included two subgroups for the type of hernioplasty (autohernioplasty or allohernioplasty). Group 1 included 135 patients (2009-2014), who underwent classical standard preoperative care; main group 2 82 patients (2015-2017), underwent innovative improved preoperative care.

Results and Discussion. After the application of the proposed development and innovative approaches, the quality of life of patients with postoperative ventral hernias undergoing hernioplasty in the main group improved in contrast to the patients in the comparison group.

Key words: postoperative ventral hernia; pneumo-bandage; duplicate suture; quality of life.

\section{С. С. ДАВЛАТОВ}

Самаркандський державний медичний інститут, Республика Узбекистан

\section{ОЦІНА ЯКОСТІ ЖИТТЯ У ВІДДІЛЕНОМУ ПЕРІОДІ У ХВОРИХ ІЗ ПІС.ЯОПЕРАЦИЙНИМИ ВЕНТРАЛЬНИМИ ГРИЖАМИ}

\footnotetext{
Мета роботи: аналіз якості життя пацієнтів за удосконаленою шкалою у хворих із післяопераційними вентральними грижами. Матеріали і методи. Основу для дослідження склали 217 пацієнтів із післяопераційними вентральними грижами, які спостерігалися та проходили лікування в хірургічних відділеннях 1-ї та 2-ї лікарень Самаркандського державного медичного інституту в 2009-2017 роках. Хворих було розділено на дві групи, які залежно від виду герніопластики (автогерніопластика чи алогерніопластика) були поділені на дві підгрупи: 1 - група порівняння - 135 хворих (2009-2014 рр.), яким застосовували стандартні заходи передопераційної підготовки; 2 - основна група - 82 пацієнти (2015-2017 рр.), при лікуванні яких застосовували удосконалений алгоритм вибору оптимального способу хірургічного лікування.

Результати дослідження та їх обговорення. Після застосування запропонованих розробок та інноваційних підходів якість життя хворих із післяопераційними вентральними грижами, які перенесли герніопластику, покращилась, на відміну від пацієнтів групи порівняння.
}

Ключові слова: післяопераційні вентральні грижі; пневмобандаж; дублікатурний шов; якість життя. 